\title{
A Thematic Analysis of Sports Bettors' Perceptions of Sports Betting Marketing Strategies in the UK
}

\author{
Elizabeth A. Killick ${ }^{1}$ (D) Mark D. Griffiths ${ }^{1}$ \\ Accepted: 21 September 2020 / Published online: 16 October 2020 \\ (C) The Author(s) 2020
}

\begin{abstract}
In the UK and other countries in the world, the volume of gambling advertisements is increasing, as is the popularity of online sports betting. While there is increasing research examining the content of such advertising, there is little research examining what gamblers themselves think about such advertising. Consequently, the aim of the present study was to firstly, explore the attitudes and opinions of sports bettors in response to marketing techniques used by the gambling industry and secondly, explore the perceived impact advertising has on their sports betting behavior. Semi-structured interviews were conducted with a sample of 19 UK sports bettors aged between 21 and 32 years old. Thematic analysis (TA) was used to analyze the transcripts. The analysis identified three main themes: (i) "temptation to gamble," (ii) "promotion characteristics of gambling," and (iii) "regulating gambling advertising." Each theme consisted of two or three subthemes that illustrated the underlying factors that were perceived to be important aspects that contributed to the opinions and attitudes towards the advertising. Findings indicate that specific inducements including enhanced odds and "request-a-bet" promotions were perceived to increase feelings of control and reduce feelings of risk, in some cases resulting in the placing of impulsive bets. According to the participants, social media marketing was found to be intrusive and the frequency of gambling advertising contributed to the normalization of betting. The present study highlights the need for further research into the efficacy of current advertising regulations in the UK, with the end goal of minimizing gambling-related harm.
\end{abstract}

Keywords Sports betting $\cdot$ Sports betting advertising · Gambling marketing $\cdot$ Thematic analysis

Elizabeth A. Killick

Elizabeth.killick2017@my.ntu.ac.uk

Mark D. Griffiths

mark.griffiths@ntu.ac.uk

1 International Gaming Research Unit, Psychology Department, Nottingham Trent University,

Nottingham, UK 
In recent years, there have been various technological advances and innovation introduced by the gambling industry which has resulted in a number of new online gambling products widely available on mobile devices and via other hardware, which have transformed the way in which individuals interact with gambling products (Gainsbury 2019; James et al. 2017; Lawn et al. 2020). Research suggests that the rise in the availability and accessibility of opportunities to gamble is associated with increased levels of gambling-related problems, although the impact is moderated by other factors (Reith 2012). As well as an increase in the type and availability of gambling products, there has been an increase in the frequency of gambling advertisements.

In the United Kingdom (UK), Ipsos MORI (2019) reported that the amount of money spent on gambling advertising had increased from $£ 264,657,325$ in 2015 to $£ 328,945,916$ in 2018 (a $24 \%$ increase) across various media platforms, particularly for lotteries and bookmakers. Given the popularity of sports betting, as well as the large audiences attracted to live sporting events, the broadcast of wagering advertisements appears to have become widespread, especially during televised sporting events (Columb et al. 2020; Hing et al. 2015; Lole et al. 2019; Lopez-Gonzalez et al. 2017; Purves et al. 2020). For example, during the 2018 FIFA (soccer) World Cup, betting advertisements were the most prevalent type of advertisements shown, totaling almost 90 min of screen time during the tournament (Duncan et al. 2018). Therefore, the impact of gambling advertisements, particularly those shown during sporting events, is being increasingly recognized as an important area for research, with the aim of minimizing gambling-related harm.

Previous research has reported that viewing sports betting advertising is associated with an increased desire to gamble among low-risk, moderate, and problem gamblers (Hing et al. 2014a, 2015; Sproston et al. 2015). Qualitative studies have reported an association between sports betting advertising and sports betting-related attitudes. Sports betting advertising seemingly influences gambling attitudes by normalizing sports betting perceptions held by adults (Deans et al. 2017; Thomas et al. 2012), young people (8-16 years Djohari et al. 2019), and children (Pitt et al. 2016; Thomas et al. 2016). Additionally, it has been argued that sports betting advertising prematurely exposes young people to advertising (Djohari et al. 2019; Ipsos MORI 2020; Thomas et al. 2018).

Research into the type of wagering inducement promotion has found some inducement types to be more popular than others, for example, for sports bettors often favor the "risk-free" or reduced risk inducement (Hing et al., 2014a, 2017, 2019; Lole et al. 2019). Other research has reported that both treatment-seeking sports bettors and general population sports bettors were encouraged to spend more due to advertising, particularly in response to free bet and deposit offers (Hing et al. 2015). In a sample of Spanish sports bettors undergoing treatment for gambling disorder $(n=43)$, several promotions including bonuses, enhanced odds, and money back promotions were found to be particularly persuasive forms of marketing techniques used by gambling operators (Lopez-Gonzalez et al. 2020).

One of the new online sports betting functionalities that has changed the way in which sports bettors interact with betting products is a novel gambling feature called "custom sports bets" (CSBs), which offers bettors the facility to create their own unique bets. By offering the facility for sports bettors to customize their own bets, Lopez-Gonzalez et al. (2019) argued that the engagement produced through this option, whereby the bettors engaged in the activity of producing the betting slip rather than just waiting for the sporting event to unfold, could facilitate the "illusion of control." However, recent research by Newall et al. (2020) of online sport/race bettors $(n=789)$ did not find a significant correlation between the frequency of placement of these types of bets and an illusion-of-control scale. However, CSB use was found 
to be positively correlated with problem gambling severity, gambling harms, and gambling consumption.

To date, the majority of research investigating the impact of gambling advertising has been carried out in Australia (e.g., Hing et al. 2013, 2014a, b, 2018; Lamont et al. 2016; Russell et al. 2018), while there is still only a limited understanding of this issue in the UK. While there is increasing research examining the content of such advertising, there is little research examining what gamblers themselves think about such advertising, particularly outside of Australia. Further information about how sports betting marketing strategies influence gambling behaviors is required in order to inform suitable policy and regulatory responses to prevent gambling-related harm in the UK. Therefore, the present study qualitatively explored participants' perceptions of gambling advertising. Given the high volume of gambling advertisements displayed during live sporting events, including shirt-sponsorship and pitch-side hoarding and advertisements for in-play betting odds, the present study sought the opinion of in-play sports bettors. The specific objectives of the present study were to explore participants' opinions and attitudes towards (i) sports betting advertising and (ii) sports betting marketing techniques used by gambling operators.

\section{Methods}

\section{Procedure}

Data were collected between August 2018 and January 2019. Participants were interviewed face-to-face at a location of their choice and four interviews were conducted by telephone. To be eligible to participate in the study, individuals were required to have placed at least one inplay sports bet online within 6 months prior to the interview taking place. The reason for this was to ensure that participants were more likely to have been exposed to different forms of gambling advertising and new betting innovations, particularly sponsorship and in-play based betting promotions. Interviews were semi-structured and varied in length between 25 min and $1 \mathrm{~h}$, with an average of $38 \mathrm{~min}$. All interviews were recorded using a digital voice recorder, with informed consent from participants. Participants were asked questions about the selfperceived impact of advertising and gambling promotions on their gambling behavior (full interview schedule available on request to the first author).

Participants completed a demographic information sheet and problem gambling behavior was assessed using the Problem Gambling Severity Index (PGSI; Ferris and Wynne 2001). This self-assessment of gambling behavior and consequences in the previous 12 months resulted in participants being categorized into one of the following groups based on PGSI score: non-problem gambler (scoring 0), low-risk gambler (scoring 1-2), moderate-risk gambler (3-7), or problem gambling (8 or more). The study's main goal was to explore participants' own accounts of their sports betting behaviors rather than defining these behaviors entirely through a screening "score." Therefore, the PGSI was used in order to indicate the level of gambling that participants were involved in and to explore whether there were any differences in qualitative responses between groups of individuals. The PGSI was used because it was specifically designed for the general population and has been found to be valid in assessing problem gambling severity in a non-clinical context (Holtgraves 2009). However, the PGSI groupings must be treated with some caution as they cannot be seen to sufficiently explain broader gambling behaviors for the participants. In the present study, two participants 
scored in the "moderate risk" PGSI group, and also described patterns of excessive sports betting that were not picked up by the PGSI. Furthermore, two participants said they had had gambled infrequently in the previous 12 months and scored in the "moderate risk" PGSI group, and also described themselves as problem gamblers because of a self-perceived previous "addiction" to sports betting.

\section{Participants}

Participants were recruited using convenience sampling, advertisements on the authors' university website, and snowball sampling to generate additional participants. Participants were recruited from across the UK including Nottingham, London, Bristol, Birmingham, Derby, York, Leeds, Sheffield, Oxford, and Dundee (see Table 1). Ethical approval was granted from the research team's University Ethics Committee prior to the study commencing. In total, 17 of the participants were male. Four were no-risk gamblers, seven were low-risk gamblers, seven were moderate-risk gamblers, and one was a problem gambler. Ages ranged from 21 to 32 years $($ mean $=25.5$ years; $\mathrm{SD}=3.25)$.

\section{Data Analyses and Theoretical Approach}

Interviews were recorded and all of the content was typed verbatim into Microsoft Word, and analyzed using QSR NVivo (Version 12), a qualitative data analysis computer software package. Nobody was offered compensation for participation. A qualitative method was used for the present study because it allows researchers to explore a "complex setting and complex interaction" (Sofaer 1999, p.1105). A thematic analysis approach was used (Braun and Clarke 2006) which involved examining the data to identify the common themes, topics, ideas, and patterns of meaning that come up recurrently. Braun and Clarke (2006) suggest that thematic analysis is a useful research tool due to its theoretical freedom and has the ability to deliver a

Table 1 Basic demographic information of participants $(n=19)$

\begin{tabular}{llll}
\hline Participant & Gender & Age & PGSI score \\
\hline 1 & Male & 30 & 7 (moderate) \\
2 & Male & 30 & 2 (low) \\
3 & Male & 26 & 5 (moderate) \\
4 & Female & 24 & 0 (no-risk) \\
5 & Male & 25 & 0 (no-risk) \\
6 & Male & 26 & 5 (moderate) \\
7 & Male & 29 & 2 (low) \\
8 & Male & 30 & 2 (low) \\
9 & Male & 24 & 4 (moderate) \\
10 & Male & 25 & 1 (no risk) \\
11 & Male & 30 & 1 (no-risk) \\
12 & Male & 30 & 3 (moderate) \\
13 & Male & 21 & 13 (problem gambler) \\
14 & Male & 31 & 4 (moderate) \\
15 & Female & 21 & 2 (low) \\
16 & Male & 24 & 1 (low) \\
17 & Male & 32 & 2 (low) \\
18 & Male & 26 & (moderate) \\
19 & Male & 26 &
\end{tabular}


"rich and detailed, yet complex, account of the data" (p.78). This method was chosen because it was thought as being best able to describe the experiences of the participants. The rationale behind the choice of using this specific analytic technique was that it would suit the exploratory nature of the study. The main steps were as follows: (i) familiarizing the data, (ii) generating initial codes, (iii) searching for themes, (iv) reviewing themes, (v) defining and naming themes, and (vi) producing the report. An inductive thematic analysis procedure was adopted, whereby transcripts were read, re-read, and coded line-by-line. Ideas which reappeared across multiple interviews or which represented an important idea related to the research aims were identified as categories. As each new category was identified, previous transcripts were re-read for relevant material. The research team met regularly to discuss the emergence of major themes. New prompts and areas for investigation were included in the interview schedule as they emerged. We refined themes and discussed any differences in interpretation until agreement was reached by the authors. Expressions are used to indicate approximate endorsement: "most" (16 or more participants), "many" (10-15 participants), "some" (4-9 participants), and a "few" (three or fewer participants).

\section{Results}

Based on the analysis, the themes that emerged were categorized under the broad concepts of (i) temptation to gamble, (ii) promotion characteristics of gambling, and (iii) regulating gambling advertising. Each concept had sub-themes (see Table 2).

\section{Theme 1: Temptation to Gamble}

The two sub-themes for temptation to gamble were (i) enticement and (ii) unavoidable. The first theme concerned participants' perceptions of how particular gambling advertisements encouraged them to place bets. The second theme concerned participants' feelings that the advertisements were inescapable via specific media channels.

\section{Enticement}

This first sub-theme of temptation concerned how advertisements encouraged feelings of being attracted to sports betting. For example, many participants described how the advertisements grabbed their attention and "made them think about betting". In some cases, this influenced participants enough to place a bet. For example:

Table 2 List of themes and sub-themes

\begin{tabular}{ll}
\hline Theme & Sub-theme \\
\hline Temptation to gamble & Enticement \\
Promotion characteristics of gambling & Unavoidable \\
& Attractive odds \\
Regulating gambling advertising & Brand awareness \\
& Normalization of betting \\
& Responsible gambling messages \\
& Protecting children \\
\hline
\end{tabular}


If I'm watching a football match and thinking about having a bet and then just the fact that there's an advert coming on advertising it, then obviously it does enter my brain and encourages me to think about it (Participant 8).

[Sports betting advertising] puts an idea [to bet] in your head (Participant 16)

It's a huge, huge thing because you're constantly tempted to go and bet, you know, they do kind of sucker you in (Participant 14).

\section{Unavoidable}

The second recurring sub-theme of temptation was the perception that there is an oversaturation of gambling advertising, particularly during live sporting broadcasts, which sports bettors often struggled to "get away from" or "escape". The frequency and unavoidability of advertisements were viewed negatively by some sports bettors. For example:

You can't really get away from [gambling advertising] (Participant 4)

I can't believe the amount of gambling adverts. Like, you get bombarded by it. Every break in between the sports is 'This is the odds now' (Participant 1)

[Gambling advertising is] a bit rammed down your throat (Participant 7)

Many participants described seeing promotions for sports wagering when they were watching football on television. It was noted that the volume of advertising was higher during football matches in comparison with other sporting events. For example:

There's a lot of adverts when the football is on. At half-time, before the second half. It's everywhere (Participant 18).

I'm stunned at the amount of adverts to be honest. Football is the main one I watch, so I see that one the most. When I watch UFC [Ultimate Fighting Championship] and stuff there's nowhere near as much (Participant 1).

In addition to being often shown during football matches, one participant described how sports betting television advertisements were often aligned with nationally popular events, such as large football tournaments and the Grand National horse racing:

What you tend to see is, around main events, like the Grand National, stuff like that. You get a lot more stuff on TV (Participant 10).

Although most of the interviews centered around television advertisements, another form of advertising which some participants discussed was advertising on social media. For example:

Promotions are all over my social media. I don't use Twitter that often so I don't see them on Twitter, but I see them on Instagram and Facebook-sponsored ads for gambling (Participant 9).

Another participant discussed the intrusiveness of gambling advertising on social media:

I do see Facebook have the new adverts that they put in the middle of videos and I often see William Hill. It's a halfway through, you're watching a video of whatever it is, is the, 
uh, 10, 15 seconds it pops up and yeah, it's annoying and a bit intrusive. I wish it wasn't there (Participant 15).

\section{Theme 2: Promotion Characteristics of Gambling}

The three sub-themes concerning promotion characteristics of gambling were (i) attractive odds, (ii) brand awareness, and (iii) normalization of betting.

\section{Attractive Odds}

The first sub-theme of promotion characteristics concerned participants' perceptions of how odds are advertised in a way that attracts them to placing a sports bet. The promotion of betting odds prior to commencement and during half-time breaks of live sporting events was discussed. If odds were considered "good" or "better" than other gambling providers, some participants described how this motivated them to place a bet. Monetary incentives provided by sporting betting companies are often promoted through various media sources. Participant perceptions of these promotions varied, but promotions which appeared to particularly appeal to sports bettors were new customer welcome offers, enhanced odds (where a bookmaker boosts the usual betting odds of a selection), and customized sports bets. Some participants described how these promotions decreased their feelings of risk in terms of financial loss. For example:

You just think that you're going to win more because the odds are better. It almost feels like it's a guarantee but it's not (Participant 2).

Additionally, promotions created the perceptions that the individual had more control over the outcomes and therefore more likely to win. For example, with "request-a-bet" odds, where participants get to choose the exact markets that they want to bet on:

That's why I like the 'Price It Up' one [a specific name of a request-a-bet offer]. Because you can completely control everything. You can say whether you think there is going to be like yellow cards and corners (Participant 4)

Sky Bet does their request a bet thing where people can request a bet online and then people engage with that because they think they're really good odds and they're more likely to bet on them (Participant 14)

One element of gambling advertisements that attracted many participants to place a bet was the odds incentives that were being advertised by the betting companies, and one specific promotion that was favored by sports bettors was "enhanced" odds. Participants described their temptation to gamble, through what appears to be a process of decision-making. Participant 9 commented that "boosted odds" made him feel like there was more of a likelihood of the bets winning, which participants questioned. This tempting element of promotions from gambling advertisements caused participants a dilemma of whether or not to place a bet. For example:

It's the boosts that get me. Those price boosts. They're the devil (Participant 1)

You may not have been watching the football. You may not have been thinking about betting. And then you're watching the adverts and the adverts come on and it says 
'Sergio Agüero to score next was 7/2 and now... you know 9/2' and you think 'that's not bad, you know?' (Participant 6)

It will be 'Oh Manchester City are playing Brentford today' and 'we've got great odds' it's 5/1 or whatever with a [maximum] stake of a fiver [£5] and you think 'oh it's guaranteed money' (Participant 9)

Say if the odds were like 4/1, it might increase to 7/1, and then obviously I'll be looking to see if I think it's going to come through (Participant 8).

Participants also discussed how the availability and visibility of these adverts attracted them to place a bet. For example:

So, you see what the odds were, and what they are now and then it just clouds your judgement because suddenly you're playing the odds, not what you think will actually happen. Because they're just up there, in yellow and it's like 'here's the boost' and it always sways my bet a bit (Participant 1)

It's quite overwhelming the amount of things you can bet on. There's loads. So to have that...I know it's probably, it's probably incorrect, not incorrect...false...false advertising almost. Do they actually increase the odds? I don't know. But because it's in like big 'oh increased odds' shouting and screaming at you, you think 'oh, why not?' (Participant 16).

However, a few participants were skeptical of these specific offers and did not seem to be impacted by the prices that were available:

I mean they're nice prices. But if I'm watching the game and they say 'so and so is going to score the next goal' and I'm like 'well, no, he's not', I don't care if it's 8 or 9-1, I'm not going to bet on it (Participant 4)

I don't really buy into it as much that it is actually a true reflection of what the original odds were. It's very easy to say otherwise but...it definitely draws you to the bet (Participant 11)

\section{Brand Awareness}

The second sub-theme of promotion characteristics concerned brand awareness. When discussing gambling advertisements, some sports bettors described a number of characteristics and promotional strategies that were used by sports betting operators to attract them to place bets. Financial incentives were used to attract sports bettors which included "free bet" promotions. For example:

Most of them that are on TV are usually adverts about new customer offers. It's usually around a specific event, like a game that's on (Participant 13)

I used to bet with William Hill...now the app I use is Bet Victor and I only got into that because I saw an advert they were doing. It was like if you bet the first goal scorer and then the minute of the goal, it's like a ridiculous amount that they win, and you get one free bet every time they do it and me and my sister saw that and she was like 'oh even I'd try that', so I got onto that site and that's how I got onto it (Participant 4). 
Another promotional incentive was welcome offers, which a few participants described as an attribute that contributed to participants creating a betting account:

So you'll register a betting account. And you'll think 'well I've got a bit of an incentive to get with this company. I'll probably get that with other accounts as well and then that might turn into 3 or 4 with welcome bonuses, or whatever, from different companies' but most of the time I think I settle into the one company (Participant 3).

Participants described how brands were associated with specific advertising strategies, and described how these strategies distinguished brands from one another. Advertisements for sports betting were found to be memorable and resulted in an increased awareness of gambling products. Participants described marketing strategies associated with particular brands. These included memorable features that allowed them to recall details of the advertisements, including description of specific characters, betting markets, and promotions that were being implemented. For example, the "In-play with Ray" advertisements, with (well-known British actor) Ray Winstone promoting in-play betting for Bet365:

The one that advertises with Ray Winstone, that one springs to mind (Participant 8)

They certainly worked with in-play betting because the one that sticks in my head is with Ray. I didn't know his surname, Ray something and it's Bet365 I think. He's a bit of geezer and he's going 'oh, this is the latest one'. You know, that one sticks in my mind (Participant 16).

One participant described how they had more trust in a betting product because it used a sports figure that they admired. In the following example, the participant refers to Liverpool football club manager Jürgen Klopp:

I love him and I just think...even though you think he's just doing it because it's money you think you wouldn't advertise something terrible because Klopp's funny. He wouldn't do that (Participant 4).

Some brands created positive feelings and were perceived by bettors as more entertaining than others. For example, Paddy Power was described as sending "risky" and "humorous" social media marketing messages:

They use big named faces...so you can remember who they are and which company they are advertising I guess. I think they generally can be amusing...Paddy Power in particular. They don't seem to go for as much on TV advertising but there is some amazing advertising on social media of them doing things like paying out silly bets that haven't actually won. But personally, I think that is quite genius (Participant 16)

Paddy Power tend to...I don't know the best way to describe it...not necessarily push the boundaries but they...they advertise and obviously they have adverts but then I know they obviously work because they're the first ones I've gone to talk about...but they're kind of...they're a bit risky, generally (Participant 6).

One participant described how advertisements presented characters in a positive manner, suggesting that there could be success with gambling and minimizing potential risks. Therefore, the advertisements may influence people to bet by creating a perception that there is a higher chance of winning: 
The ones I've seen they kind of make them look really attractive...like the people they use in the adverts. It's always really happy, well-off type of people. They don't advertise the negatives of it at all. It's more like you're definitely going to win (Participant 7)

There's like a Ray Winstone...I think it's Bet365 advert... and yeah it does show like a lavish lifestyle and stuff which isn't true but it does say at the bottom 'gamble responsibly' (Participant 10).

\section{Normalization of Betting}

The third sub-theme of promotion characteristics concerned normalization of betting. Many sports bettors commented on how prevalent and acceptable sports betting had become, especially in the context of football betting and that advertising has contributed to the normalization of gambling. For example, the wide availability of gambling advertisements, including the frequency and type of advertisements, particularly during live football matches, was seen to encourage the idea that sports betting is an activity that was typical for sports fans to take part in and it was heavily connected with the sporting activity. One participant commented on how they were more likely to pay attention to a gambling advertisement when it was on during a football match. The alignment of the advertisement with the sports being viewed resulted in the advert receiving attention from the participant:

I never really pay attention to the adverts when they're just on TV...but you definitely notice them when you're watching sports (Participant 10).

Some participants also discussed how gambling had become ingrained within the sport, for example:

The football is normally sponsored by a gambling company and then the next advert is a gambling thing, and then they'll be one more gambling advert, and then it's back to the sponsor of the game, and then you're back to the football (Participant 1)

They use it to get a bit of publicity if they've got it on their shirts, or on the screens behind them. I think it's just normal for that to happen (Participant 13)

The content of some advertisements allowed a few participants to feel more comfortable placing a bet, in part due to the relaxed nature of some adverts. Others commented on how there were also positive qualities in the advertisement that were emphasized. For example, participant 2 described how advertisements were "relaxed" and "light-hearted" and as a result felt more comfortable placing a bet. Again, this could imply a feeling that there is less involvement of risk:

You just feel like it's OK to put a bet on because it's just a bit of fun. The videos are quite relaxed and light-hearted (Participant 2).

\section{Theme 3: Regulating Gambling Advertising}

The three sub-themes for regulating gambling advertising were (i) responsible gambling messages, (ii) protecting children, and (iii) industry comparisons. This theme concerned 
participants' perceptions of and their attitudes towards harm reduction strategies used by the gambling industry.

\section{Responsible Gambling Messages}

The first sub-theme of regulating advertising concerned brand awareness. What was evident from the interviews was the belief that online gambling companies were not concerned with protecting consumers from gambling-related harm, especially vulnerable individuals. Opinions centered on the responsible gambling warning messages in gambling advertisements. Despite many television advertisements including a warning message, participants seemed to be somewhat cynical about the usefulness of these. Many participants raised doubts regarding the efficacy of the warnings and found them mistimed within the advert and not sufficiently long enough in duration. Participants expressed that they did not perceive the responsible gambling warning messages that appears at the end of advertisements to be an effective method of preventing problematic gambling behavior. For example:

It's only at the end of their adverts that they tell you, which is about two seconds long, you know, 'please gambling responsibly'. And that's it (Participant 14).

A few participants suggested that they did not pay attention to the information provided at the end of the advertisements and also reported little change in their behavior as a result of the messages. For example:

If it's already grabbed you then you're not listening anymore by the time... if they say 'oh we've got this, this, and this offer' we'll put this on for these odds' you're already gone, you're already on it. I feel like it's too late (Participant 4).

One participant praised a particular gambling advertisement that displayed a responsible gambling message at the beginning of the advert, rather than at the end:

They've got Jeff Stelling. He does it and he's stood in front of a big screen where they talk about their betting app. I can't remember exactly what it is but they start with telling you that it should be fun and not be bad, whereas everyone else just ends with 'Gamble Aware'...I remember making a point about it and said to my fella 'that's good', because we know somebody who's got a problem with gambling. I said that's good. All adverts should start with the disclaimer at the start rather than at the end (Participant 4).

\section{Protecting Children}

The second sub-theme of regulating advertising concerned protecting children. This theme demonstrated the perceptions that adult sports bettors had on how gambling may influence children's gambling behavior. Some participants raised concerns about the impact gambling advertising has on young people, particularly those who are not legally allowed to gamble. For example:

I think a lot of young impressionable people might be watching football with their parents (Participant 9). 
Additionally, some participants discussed the intrusiveness of gambling advertising on social networking sites, such as Facebook, Instagram, and Twitter, and that these advertisements may appeal to children. For example:

Underage people can have access to social media. It's almost like drinking in the sense that when you become a teenager you want to do stuff you're not allowed to do...so people seeing things advertised that they can't do will make them want to gamble when they're older which I don't think is a good thing (Participant 17).

Some perceived that gambling operators had a responsibility to ensure that young children were not exposed to gambling advertisements, for example:

I think only if you're an experienced gambler, you know what your limits are. You know how much you should gamble and you should know, you know you should gamble responsibly. But for a kid starting out, 18-year-old me and he's gambling online, people generally ignore these responsible betting adverts. What I would say is maybe they don't do enough to protect younger people, more impressionable people and they don't really, they should protect them a bit more (Participant 14).

\section{Industry Comparisons}

The third sub-theme of regulating advertising concerned industry comparisons. Many of the participants had negative opinions about sports betting advertising appearing during sporting events. Participants perceived that advertising can encourage some individuals to gamble excessively, particularly problem gamblers. Some participants did not believe that the current gambling regulations were enough to protect individuals from gambling-related harm. Some participants said that they believed that gambling advertising should be banned completely, similar to that of the tobacco industry, while others made comparisons between restrictions for other products such as alcohol and fast food.

I think eventually it shouldn't be allowed, like going along the lines of cigarettes and tobacco and that...I don't agree with the advertising of any kind of betting really (Participant 8).

One participant discussed how they thought that fast food advertising was more detrimental than gambling and alcohol advertising because gambling advertisements are required to include responsible gambling information, whereas they did not believe that there was enough support for people "with a fast food addiction":

I think it comes down to individual impulsivity with gambling. I don't think it's down to advertising. I think it's different to maybe food addictions and stuff. Like, I think fast food advertising and stuff like that is way worse than gambling advertising myself (Participant 10).

When asked for opinions on any changes that they thought should be made to gambling advertising regulations, some participants believed that advertising should be removed completely. Others discussed how it was down to each individual to ensure that they gamble responsibly, and not that of the gambling company. 
There's a lot of people out there who do have problems with and having it flaunted in their face is a bit like anyone with an addiction, like alcohol, if it's thrown in your face then you're going to be all over it, aren't you? (Participant 17).

Other participants had the opinion that it was not just the gambling companies that needed to be doing more and it was down to the individual to take control of their gambling behavior:

I don't think that [gambling operators] offer enough support, but then really, is it their responsibility? It's you know like, pubs don't have Alcoholics Anonymous in the corner. Like, 'oh here's your aftercare for that'. It's not really their responsibility but I do believe that it's very easy to sink into online gambling. But I don't know, I think that you have to take some personal responsibility (Participant 1).

\section{Discussion}

The present study explored UK sports bettors' perceptions of marketing tactics used by the gambling industry, and the ways in which they perceived it to influence sports betting behavior. Based on the thematic analysis, three broad themes emerged (temptation to gamble, promotion characteristics of gambling, and regulating gambling advertising) comprising of eight sub-themes in total (Table 2). One prevalent form of marketing was the advertising of betting odds, particularly in-play odds and boosted odds. Advertisements promoted these incentives to capture the attention of sports bettors and influence sports betting behavior. It has been previously argued that the advertising of gambling during a sports match encourages impulse bets and that within advertising messages, the betting operators' logos and website addresses are easy to identify which allows gamblers to immediately respond to this marketing message (Milner et al. 2013). Furthermore, previous research has suggested that in-play sports betting has the potential to be more harmful that other forms of betting and may encourage impulse bets, especially among those experiencing gambling problems (Killick and Griffiths 2018).

Other incentives that were discussed included promotional offers, such as "welcome offer" free bets and "request-a-bet" odds. In the present study, sports betting promotions minimized perceptions of risk and encouraged feelings of control, and participants acknowledged that these promotions influenced their overall gambling intentions. Previous research has reported that promotions may reduce feelings of perceived risk that is usually associated with gambling (Thomas et al. 2015). The "request-a-bet" feature allows bettors to propose specific selections for their sports bet to a gambling operator. Because a request is initiated by the individual, it has been argued that this may result in the internalization of the locus of control (LopezGonzalez et al. 2019).

Boosted and enhanced odds were another popular form of inducement that attracted lowrisk gamblers, moderate-risk gamblers, and problem gamblers to place a bet. Participants were most aware of these promotions during advertisement breaks for televised sporting events and on gambling operator's websites. It was observed that gambling companies used marketing tactics that included highlighting these odds in yellow and positioning them on the front page of online bookmaker websites, in order to grab the gamblers' attention. Previous research has reported that on Twitter, enhanced odds were among the most frequently tweeted forms of promotion (Killick and Griffiths 2020). Advertisers generate audience engagement by using 
technologies to reach customers with highly relevant advertisements based on what they do, while placing advertisements adjacent to contents expected to be visited by target consumers (Wang 2006). These findings also support the recent evidence that has reported that bonuses, including price-related gambling promotions, have been found to be particularly persuasive for encouraging gambling behavior for those experiencing gambling-related problems (LopezGonzalez et al. 2020).

Some participants' betting behavior was influenced by seeing marketed increases in the returns being offered by the bookmaker, where they were informed that the odds had been increased (e.g., "was 7/1, now 9/1"). Transaction utility theory (Thaler 1985) proposes that the basic premise of a consumer's behavior depends not only on the perceived value of the goods and services available relative to their respective prices but also on a comparison of actual prices with reference to other prices such as the regular price. That is, individuals are affected by relative changes from reference price. Additionally, consumers are likely to make impulse purchases based on price or special promotional offers (Park et al. 2012). Therefore, these promotions may be initiating online impulse gambling behavior. The uptake of wagering inducements has been previously found to predict impulse betting among problem gamblers and frequent sports viewers (Hing et al. 2018) and gambling operators will often advertise recently "improved" or "flash odds," sometimes with a reduced time-frame, which makes the bet appear more urgent (Newall et al. 2019). The present exploratory study found these promotions appeared to change betting behavior, but further research is required to examine how such promotions change betting behavior.

In the present study, sports betting adverts used tactics designed to create an awareness for their brand, which included the use of celebrities in their television advertising and "humorous" social media marketing strategies. Social media marketing was also described as "intrusive" and "annoying," while others voiced concerns about young people being prematurely exposed to these online betting adverts. The popularity of social media combined with the nature of personalized targeted advertising meant that it was often difficult for participants to avoid them. Previous research has reported that consumers feel that personalized targeting poses a threat to one's data privacy (Brinson et al. 2018). Raymen (2019) argued that the underpinning algorithms of social media have resulted in a "technological unconscious" in which sports bettors are faced with their "unconscious desires" and presented with advertisements for betting, therefore making any efforts stop or reduce gambling increasingly difficult for both non-problem and problem gamblers.

Previous research has found that the saturation of marketing during sports matches and on televised programs influences young men's views that gambling was a regular part of sports (Deans et al. 2017). It has long been claimed by scholars and anti-gambling lobby groups that the nature of gambling advertising has a "normalizing" effect (Griffiths 2005). It has also been argued that the promotion of gambling has become a social norm (Parke et al. 2014) and it makes attitudes in society more positive and socially accepting of gambling (Thomas et al. 2012). Consequently, gambling is portrayed as a normal, enjoyable form of entertainment that is fun and exciting. While there is nothing inherently wrong with these associations, such marketing practices appear to lead to the expectation that the opportunity to gamble should naturally accompany all sporting activities. It is possible that this perception of betting being a normal and arguably inextricable part of sport may influence the uptake of betting (Djohari et al. 2019).

When comparing the study findings across all PGSI groups, all sports bettors were in agreement that there was an over-saturation of sports betting advertising, and this exposure 
was heavily intertwined with their sports watching. Previous research has suggested that advertising may be especially influential in "impulse" gambling behaviors of problem gamblers (Binde 2009); the present study suggests that inducements using odds promotions (e.g., request-a-bet, enhanced and boosted odds) may encourage increased urges to gamble for lowrisk, moderate, and problem gambler sports bettors. Therefore, regulation is required to restrict the marketing of these particularly persuasive types of promotions.

Sports bettors in the present study were critical of gambling-related risk information that was presented alongside sports betting adverts. It has previously been suggested that responsible gambling messages are likely to be ignored when shown alongside mostly positive portrayals of gambling elsewhere in the advert (Parke et al. 2014). Therefore, Parke et al. (2014) suggest that this information is displayed asynchronously rather than at the same time as the advertisements. Newall et al. (2019) found that the "When the FUN stops, stop gambling" warning messages (which are presented alongside sports betting advertisements on online gambling operator's websites) did not have a significant effect on gambling behavior. However, further empirical research is required in order to examine the impact of responsible gambling campaigns on different media sources, for example, television advertisements.

\section{Limitations}

The present study has a number of limitations. First, the study recruited sports bettors prior to the implementation of the "whistle-to-whistle" television restrictions. In 2019, the UK gambling industry volunteered to remove advertisements during live sports broadcasts, excluding horse racing. Therefore, the participants may have had a greater level of exposure to advertising and marketing than if the study was replicated now. Consequently, their views, particularly towards the frequency of television advertising, may not be applicable to those who view sports betting now. The use of convenience and snowball sampling techniques in this study resulted in a high proportion of young male sports bettors. This is not seen to be a major issue because this is a demographic found to regularly engage in sports betting, but future research could still seek to interview more females and or/older participants as these sub-groups may have different perspectives towards sports betting advertising. Furthermore, the present study specifically targeted individuals who had placed at least one in-play sports bet within the past 6 months. For this reason, participants may have had varied levels of engagement with sports betting and although they were assumed to qualify and meet the aims of the study, they were not representative of all online sports bettors or the wider betting population.

Previous research has found gambling advertising to have more of an impact on gambling involvement for problem gamblers when compared with non-problem gamblers (e.g., Gainsbury et al. 2016; Hanss et al. 2015). The sample of adult sports bettors used in this study consisted of only one problem gambler. It has previously been suggested that it is important to differentiate and understand the impact of numerous forms of advertising on different population subgroups so that educators, researchers, regulators, and legislators can respond accordingly (Binde 2009). Future research could address this by exploring how responses to gambling advertisements vary between problem gamblers and non-problem gamblers. 


\section{Conclusion}

The present study examined the perceived impact of sports betting marketing among a sample of UK sports bettors. To the best of our knowledge, this is the first study to qualitatively examine the perceived impact of gambling marketing among UK sports bettors. The results demonstrated evidence of two distinct types of wagering inducements that were particularly influential on sports betting behavior (i.e., custom sports bets and enhanced/boosted odds). These inducements were found to have distinct attributes that were attractive to the sports bettor including increased feelings of control and reduced feelings of risk that may encourage in-play sports betting. These advertised products were found to be unavoidable, being frequently offered through the websites of online operators, television advertisements, and social media sites. Although gambling companies have taken a first step by implementing a voluntary "whistle-to-whistle" advertising ban and a ban on "bet-now" advertisements, policymakers need to consider additional harm-reduction strategies that also include these particularly influential types of promotion and the additional channels in which they are marketed.

Author Contributions Elizabeth Killick and Mark Griffiths wrote the paper.

\section{Compliance with Ethical Standards}

Conflict of interest The first author declares that she has no conflict of interest. The second author's university currently receives research funding from Norsk Tipping (the gambling operator owned by the Norwegian Government). The second author has received funding for a number of research projects in the area of gambling education for young people, social responsibility in gambling and gambling treatment from Gamble Aware (formerly the Responsibility in Gambling Trust), a charitable body which funds its research program based on donations from the gambling industry. The second author also undertakes consultancy for various gaming companies in the area of social responsibility in gambling.

Ethical Approval All procedures performed in studies involving human participants were in accordance with the ethical standards of the institutional research committee and with the 1964 Helsinki declaration and its later amendments or comparable ethical standards.

Open Access This article is licensed under a Creative Commons Attribution 4.0 International License, which permits use, sharing, adaptation, distribution and reproduction in any medium or format, as long as you give appropriate credit to the original author(s) and the source, provide a link to the Creative Commons licence, and indicate if changes were made. The images or other third party material in this article are included in the article's Creative Commons licence, unless indicated otherwise in a credit line to the material. If material is not included in the article's Creative Commons licence and your intended use is not permitted by statutory regulation or exceeds the permitted use, you will need to obtain permission directly from the copyright holder. To view a copy of this licence, visit http://creativecommons.org/licenses/by/4.0/.

\section{References}

Binde, P. (2009). Exploring the impact of gambling advertising: An interview study of problem gamblers. International Journal of Mental Health and Addiction, 7(4), 541-554. https://doi.org/10.1007/s11469-0089186-9.

Braun, V., \& Clarke, V. (2006). Using thematic analysis in psychology. Qualitative Research in Psychology, 3(2), 77-101. https://doi.org/10.1191/1478088706qp063oa. 
Brinson, N. H., Eastin, M. S., \& Cicchirillo, V. J. (2018). Reactance to personalization: Understanding the drivers behind the growth. Journal of Interactive Advertising, 18(2), 136-147. https://doi.org/10.1080 $/ 15252019.2018 .1491350$.

Columb, D., Wong, M., O’Mahony, V., Harrington, C., Griffiths, M., \& O’Gara, C. (2020). Gambling advertising during live televised male sporting events in Ireland: A descriptive study. Irish Journal of Psychological Medicine. Advance online publication. https://doi.org/10.1017/ipm.2020.78.

Deans, E. G., Thomas, S. L., Derevensky, J., \& Daube, M. (2017). The influence of marketing on the sports betting attitudes and consumption behaviours of young men: Implications for harm reduction and prevention strategies. Harm Reduction Journal, 14, 5. https://doi.org/10.1186/s12954-017-0131-8.

Djohari, N., Weston, G., Cassidy, R., Wemyss, M., \& Thomas, S. (2019). Recall and awareness of gambling advertising and sponsorship in sport in the UK: A study of young people and adults. Harm Reduction Journal, 16, 24. https://doi.org/10.1186/s12954-019-0291-9.

Duncan, P., Davies, R., \& Sweney M (2018). Children 'bombarded' with betting adverts during World Cup. Retrieved August 21, 2020, from: https:/www.theguardian.com/media/2018/jul/15/children-bombardedwith-betting-advertsduring-world-cup.

Ferris, J., \& Wynne, H. (2001). The Canadian problem gambling index: Final report. Ottawa: Canadian Centre on Substance Abuse.

Gainsbury, S. (2019). Gaming-gambling convergence: research, regulation, and reactions. Gaming Law Review, 23(2), 80-83. https://doi.org/10.1089/glr2.2019.2323.

Gainsbury, S. M., King, D. L., Russell, A. M., Delfabbro, P., Derevensky, J., \& Hing, N. (2016). Exposure to and engagement with gambling marketing in social media: Reported impacts on moderate-risk and problem gamblers. Psychology of Addictive Behaviors, 30(2), 270-276. https://doi.org/10.1037/adb0000156.

Griffiths, M. D. (2005). Does advertising of gambling increase gambling addiction? International Journal of Mental Health and Addiction, 3(2), 15-25.

Hanss, D., Mentzoni, R. A., Griffiths, M. D., \& Pallesen, S. (2015). The impact of gambling advertising: Problem gamblers report stronger impacts on involvement, knowledge, and awareness than recreational gamblers. Psychology of Addictive Behaviors, 29(2), 483-491. https://doi.org/10.1037/adb0000062.

Hing, N., Vitartas, P., \& Lamont, M. (2013). Gambling sponsorship of sport: An exploratory study of links with gambling attitudes and intentions. International Gambling Studies, 13(3), 281-301. https://doi.org/10.1080 /14459795.2013.812132.

Hing, N., Cherney, L., Blaszczynski, A., Gainsbury, S., \& Lubman, D. (2014a). Do advertising and promotions for online gambling increase gambling consumption? An exploratory study. International Gambling Studies, 14(3), 394 -409. https://doi.org/10.1080/14459795.2014.903989.

Hing, N., Vitartas, M., Lamont, M., \& Fink, E. (2014). Adolescent exposure to gambling promotions during televised sport: An exploratory study of links with gambling intentions. International Gambling Studies, 14(3), 374-393. https://doi.org/10.1080/14459795.2014.902489.

Hing, N., Lamont, M., Vitartas, P., \& Fink, E. (2015). Sports-embedded gambling promotions: A study of exposure, sports betting intention and problem gambling amongst adults. International Journal of Mental Health and Addiction, 13(1), 115-135. https://doi.org/10.1007/s11469-014-9519-9.

Hing, N., Vitartas, P., \& Lamont, M. (2017). Understanding persuasive attributes of sports betting advertisements: A conjoint analysis of selected elements. Journal of Behavioral Addictions, 6(4), 658-668. https://doi.org/10.1556/2006.6.2017.062.

Hing, N., Russell, M. T., Li, E., \& Vitartas, P. (2018). Does the uptake of wagering inducements predict impulse betting on sport? Journal of Behavioural Addictions, 33(2), 685-704. https://doi.org/10.1556/2006.7.2018.17.

Hing, N., Russell, A. M. T., Thomas, A., \& Jenkinson, R. (2019). Wagering advertisements and inducements: Exposure and perceived influence on betting behaviour. Journal of Gambling Studies, 35(3), $793-811$. https://doi.org/10.1007/s10899-018-09823-y.

Holtgraves, T. (2009). Evaluating the problem gambling severity index. Journal of Gambling Studies, 25(1), 105-120. https://doi.org/10.1007/s10899-008-9107-7.

Ipsos MORI. (2019). Interim synthesis report: The effect of gambling marketing and advertising on children, young people and vulnerable adults. Retrieved August 21, 2020, from: https://about.gambleaware. org/media/1964/17-067097-01-gambleaware_interim-synthesis-report_plain-english-summary-final.pdf.

Ipsos MORI (2020). Final Synthesis Report: The impact of gambling marketing advertising on children, young people and vulnerable adults. Retrieved August 21, 2020, from: https://www.ipsos. $\mathrm{com} / \mathrm{sites} / \mathrm{default} /$ files/ct/publication/documents/2020-03/gambling-marketing-advertising-effect-youngpeople-exec-summary.pdf.

James, R., O’Malley, C., \& Tunney, R. (2017). Understanding the psychology of mobile gambling: A behavioural synthesis. British Journal of Psychology, 108(3), 608-625. https://doi.org/10.1111/bjop.12226.

Killick, E. A., \& Griffiths, M. D. (2018). In-play sports betting: A scoping study. International Journal of Mental Health and Addiction, 17, 1456-1496. https://doi.org/10.1007/s11469-018-9896-6. 
Killick, E. A., \& Griffiths, M. D. (2020). A content analysis of gambling operators' Twitter accounts at the start of the English Premier League football season. Journal of Gambling Studies, 36(1), 319-341. https://oi. org/10.1007/s10899-019-09879-4.

Lamont, M., Hing, N., \& Vitartas, P. (2016). Affective response to gambling promotions during televised sport: a qualitative analysis. Sport Management Review, 19(3), 319-331. https://doi.org/10.1016/j.smr.2015.06.002.

Lawn, S., Oster, C., Riley, B., Smith, D., Baigent, M., \& Rahamathulla, M. (2020). A literature review and gap analysis of emerging technologies and new trends in gambling. International Journal of Environmental Research and Public Health, 17(3), 744. https://doi.org/10.3390/ijerph17030744.

Lole, L., Li, E., Russell, A. M., Greer, N., Thorne, H., \& Hing, N. (2019). Are sports bettors looking at responsible gambling messages? An eye-tracking study on wagering advertisements. Journal of Behavioral Addictions, 8(3), 499-507. https://doi.org/10.1556/2006.8.2019.37.

Lopez-Gonzalez, H., Estévez, A., \& Griffiths, M. D. (2017). Marketing and advertising online sports betting: A problem gambling perspective. Journal of Sport \& Social Issues, 41(3), 256-272. https://doi.org/10.1177 /0193723517705545.

Lopez-Gonzalez, H., Jimenez-Murcia, S., \& Griffiths, M. D. (2019). Customization and personalization of sports betting products: Implications for responsible gambling. Gaming Law Review, 23(8), 572-577. https://oi. org/10.1089/glr2.2019.2383.

Lopez-Gonzalez, H., Griffiths, M., Jimenez-Murcia, S., \& Estévez, A. (2020). The perceived influence of sports betting marketing techniques on disordered gamblers in treatment. European Sport Management Quarterly, 20(4), 421-439. https://doi.org/10.1080/16184742.2019.1620304.

Milner, L., Hing, N., Vitartas, P., \& Lamont, M. (2013). Embedded gambling promotion in Australian football broadcasts: An exploratory study. Communication, Politics \& Culture, 46, 177-198.

Newall, P. W. S., Walasek, L., Singmann, H., \& Ludvig, E. A. (2019). Testing a gambling warning label's effect on behavior. PsyArXiv Preprints. https://doi.org/10.31234/osf.io/dxfkj.

Newall, P. W. S., Cassidy, R., Walasek, L., Ludvig, E., \& Meyer, C. (2020). Who uses custom sports betting products? Addiction Research \& Theory. Advance online publication, 1-7. https://doi.org/10.1080 /16066359.2020.1792887.

Park, E. J., Kim, E. Y., Funches, V. M., \& Foxx, W. (2012). Apparel product attributes, web browsing, and eimpulse buying on shopping websites. Journal of Business Research, 65(11), 1583-1589. https://oi. org/10.1016/j.jbusres.2011.02.043.

Parke, A., Harris, A., \& Parke, J. (2014). Responsible marketing and advertising in gambling: A critical review. The Journal of Gambling Business and Economics, 8(3), 21-35.

Pitt, H., Thomas, S. L., Bestman, A., Stoneham, M., \& Daube, M. (2016). "It's just everywhere!" Children and parents discuss the marketing of sports wagering in Australia. Australian and New Zealand Journal of Public Health, 40(5), 480-486. https://doi.org/10.1111/1753-6405.12564.

Purves, R., Critchlow, N., Morgan, A., Stead, M., \& Dobbie, F. (2020). Examining the frequency and nature of gambling marketing in televised broadcasts of professional sporting events in the United Kingdom. Public Health, 184, 71-78. https://doi.org/10.1016/j.puhe.2020.02.012.

Raymen, T. (2019). Lifestyle gambling in accelerated culture. In T. Raymen \& O. Smith (Eds.), Deviant leisure. Palgrave studies in crime, media and culture. Palgrave Macmillan, Cham. https://doi.org/10.1007/978-3030-17736-2 12 .

Reith, G. (2012). Beyond addiction or compulsion: The continuing role of environment in the case of pathological gambling. Addiction, 107(10), 1736-1737. https://doi.org/10.1111/j.1360-0443.2012.03669.x.

Russell, A., Hing, N., Browne, M., \& Rawat, V. (2018). Are direct messages (texts and emails) from wagering operators associated with betting intention and behavior? An ecological momentary assessment study. Journal of Behavioral Addictions, 7(4), 1079-1090. https://doi.org/10.1556/2006.7.2018.99.

Sofaer, S. (1999). Qualitative methods: What are they and why use them? Health Services Research, 34(5), 1101-1118.

Sproston, K., Hanley, C., Brook, K., Hing, N., \& Gainsbury, S. (2015). Marketing of sports betting and racing. Melbourne: Gambling Research Australia. Retrieved August 21, 2020, from: https://www. responsiblegambling.nsw.gov.au/__data/assets/pdf_file/0017/138122/Marketing-of-sports-betting-andracing.pdf.

Thaler, R. (1985). Mental accounting and consumer choice. Marketing Science, 4(3), 199-214. https://doi. org/10.1287/mksc.4.3.199.

Thomas, S. L., Lewis, S., McLeod, C., \& Haycock, J. (2012). 'They are working every angle'. A qualitative study of Australian adults' attitudes towards, and interactions with, gambling industry marketing strategies. International Gambling Studies, 12(1), 111-127. https://doi.org/10.1080/14459795.2011.639381.

Thomas, S. L., Bestman, A., Pitt, H., Deans, E., Randle, M. J., Stoneham, M., \& Daube. (2015). The marketing of wagering on social media: an analysis of promotional content on YouTube, Twitter and Facebook. Victoria: Victorian Responsible Gambling Foundation. 
Thomas, S, L., Pitt, H., Bestman, A., Randle, M., Daube, M., \& Pettigrew, S. (2016) Child and parent recall of gambling sponsorship in Australian sport, Victorian Responsible Gambling Foundation, Melbourne. Retrieved August 20, 2020, from: https://responsiblegambling.vic.gov.au/resources/publications/child-andparent-recall-of-gambling-sponsorship-in-australian-sport-67/.

Thomas, S. L., Bestman, A., Pitt, H., Cassidy, R., Mccarthy, S., Nyemcsok, C., et al. (2018). Young people's awareness of the timing and placement of gambling advertising on traditional and social media platforms: A study of 11-16-year-olds in Australia. Harm Reduction Journal, 15, 51. https://doi.org/10.1186/s12954-0180254-6.

Wang, A. (2006). Advertising engagement: A driver of message involvement on message effects. Journal of Advertising Research, 46, 355-368. https://doi.org/10.2501/S0021849906060429.

Publisher's Note Springer Nature remains neutral with regard to jurisdictional claims in published maps and institutional affiliations. 